\title{
Seasonal Effect on Developmental Competence, Oxidative Status and Tubulin Assessment of Prepubertal Ovine Oocyte
}

\author{
Elisa Serra ${ }^{\dagger}$, Sergio Domenico Gadau ${ }^{*}{ }^{\dagger}$, Giovanni Giuseppe Leoni, Salvatore Naitana and Sara Succu \\ Department of Veterinary Medicine, University of Sassari, Via Vienna 2, 07100 Sassari, Italy; \\ eliserra@uniss.it (E.S.); gioleoni@uniss.it (G.G.L.); snaitana@uniss.it (S.N.); succus@uniss.it (S.S.) \\ * Correspondence: sgadau@uniss.it; Tel.: +39-07-922-9596 \\ + Elisa Serra and Sergio Domenico Gadau contributed equally to this work.
}

Citation: Serra, E.; Gadau, S.D.; Leoni, G.G.; Naitana, S.; Succu, S. Seasonal Effect on Developmental Competence, Oxidative Status and Tubulin Assessment of Prepubertal Ovine Oocyte. Animals 2021, 11, 1886 https://doi.org/10.3390/ani11071886

Academic Editors: Karen Wagener and Marc Drillich

Received: 30 April 2021

Accepted: 21 June 2021

Published: 24 June 2021

Publisher's Note: MDPI stays neutral with regard to jurisdictional claims in published maps and institutional affiliations.

Copyright: (C) 2021 by the authors Licensee MDPI, Basel, Switzerland. This article is an open access article distributed under the terms and conditions of the Creative Commons Attribution (CC BY) license (https:// creativecommons.org/licenses/by/ $4.0 /)$.
Simple Summary: Oocytes obtained from the ovaries of slaughtered prepubertal ewes can be incorporated into an in vitro embryo production system. The collection of this material is possible at two different times of the year, spring and autumn. The first period is linked to the natural reproductive cycle of the sheep. The second, on the other hand, is linked to the manipulation of the reproductive seasonality which allows the oestrus cycle to be controlled artificially. The analysis highlighted that the collection season influences oocytes quality from prepubertal donors in terms of improved energetic and oxidative status, microtubular organization, and developmental competence in oocytes recovered in spring. Data obtained underline that oocytes seem to be genetically and evolutionarily programmed to give their best in spring, this being the most favorable period for newborns.

Abstract: The reproductive seasonality of domestic animals is often manipulated in order to have more reproductive periods for commercial purposes related to the production of milk and meat. It is scientifically proven that such an alteration of the reproductive activity in sheep entails a deterioration in oocyte quality, leading to an inability to generate embryos. Since oocytes obtained from prepubertal ewes can be incorporated into an in vitro embryo production system and considering that their quality is crucial to the success of in vitro procedures, the aim of this work was to investigate the effect of seasons on the quality of prepubertal ovine oocytes collected in autumn and spring. Ovaries were collected from a local slaughterhouse from 30-40-day-old suckling lambs during both seasons. Following $24 \mathrm{~h}$ of in vitro maturation, oocytes developmental competence, reactive oxygen species (ROS) intracellular levels, and mitochondrial activity were evaluated, and a tubulin assessment was performed. The results on embryo production, as a percentage of first divisions and number of blastocysts obtained, were significantly higher in oocytes collected in the spring. Mitochondrial activity in oocytes was higher, and ROS production significantly lower, in spring than in autumn. Tubulin PTMs (tyrosinated and acetylated $\alpha$-tubulin) showed a higher immunoreactivity in oocytes collected in spring compared with autumn sampling. Our data showed that seasons may affect the developmental competence, energetic status, and tubulin assessment of oocytes recovered from prepubertal ewes. Therefore, special care should be taken when choosing the period of the year for prepuberal ovine oocytes collection aimed at in vitro embryo reproduction programs.

Keywords: oocyte; lamb; season; oxidative status; developmental competence

\section{Introduction}

According to geneticists, accelerating the reproductive rate of a breed or a single animal represents the starting point to achieve a good selection program. The application of such selection programs shows limitations in several animal species, depending on the reproductive seasonality; a sort of ancestral inheritance resulting from the adaptation achieved by animals to survive during the natural selection process. Indeed, seasonal breeding is a survival strategy adopted by many wild animals to ensure that their progeny 
are born at the most favorable time of year, with the most appropriate environmental conditions resulting in higher chances of offspring survival [1]. The reproductive seasonality also characterizes several domestic species such as sheep. Reproductive activity, controlled by photoperiod and regulated by the melatonin inhibiting Gonadotropin-Inhibitory Hormone $(\mathrm{GnIH})$ [2] and stimulating Kisspeptin-Neurokinin-Dynorphin (KNDy) neurons of the arcuate nuclei to increase Gonadotropin Releasing Hormone (GnRH) pulse patterns [3], represents the successful adaptation of these animals to natural mating for one season per year. Moreover, in Sardinia, an extension of the sheep breeding season has been obtained through distributing lambing along the year to ensure milk production for several additional months as well as to satisfy the meat market demand. This is achieved using the out-of-breeding mating strategy, which consists of interrupting sexual promiscuity by the use of the male effect and exogenous hormones for oestrus cycle control [4]. In this way the lambing calendar is modified in order to obtain 30-40-day-old lambs (weighing 8-10 kg) during the Easter and Christmas celebrations. However, and despite their wide and frequent use, these strategies may result in decreased fertility [5]. In in vitro embryo production programs (IVP) several authors have highlighted a periodic reduction in embryo yield in both cattle and buffalo [6]. Also, a decrease in oocyte quality during the non-breeding season has been shown in cats and monkeys [7,8]. As for sheep, it has been reported that seasonality influences the number of in vitro embryo production [9].

The influence of oocyte competence on embryo developmental potential is now well recognized [10]. Oocyte competence is the ability of oocytes to resume meiosis, to cleave following fertilization, and to develop to the blastocyst stage. It represents the quality marker commonly used by most laboratories [11]. Among various cellular mechanisms involved in oocyte competence, mitochondrial activity can be included [12-15] (as it is essential for energy production required for fertilization and embryo development), concentration of reactive oxygen species (ROS) $[10,14,16,17]$, and for microtubular cytoskeleton development $[18,19]$. The microtubules (MTs) and their post-translational modifications (PTMs) may have an important role during the maturation and the fertilization of the oocyte due to their involvement in the meiotic spindle assembly and the subsequent segregation, alignment, and movement of chromosomes [20]. In our previous work [21], we found that the most abundant tubulin PTMs in the meiotic spindle of ovine oocytes are tyrosination and acetylation. PTMs, as well as acetylation, characterizes more stable MTs, while tyrosination is more abundant on the more dynamic ones [22]. Therefore, the tubulin PTMs composition in the MTs of the meiotic spindle may be a crucial factor involved in oocyte competence [21,23]. Since oocytes obtained from ovaries of slaughtered prepubertal ewes can be incorporated into an in vitro embryo production system [24], and considering that their quality is crucial to the success of in vitro procedures, the present work aimed to describe a possible relationship between collection season and quality in ovine prepubertal oocytes. Therefore, in the present study the quality of oocytes collected during autumn (November-December) and spring (March-April) was investigated through an evaluation of developmental competence, mitochondrial activity, ROS intracellular levels, and a tubulin assessment.

\section{Materials and Methods}

All chemicals in this study were purchased from Sigma Chemical CO (St. Louis, MO, USA) unless stated otherwise.

\subsection{Oocyte Collection and In Vitro Maturation}

A total of 2495 in vitro matured oocytes were used: 1054 oocytes collected in autumn (November-December) and 1441 oocytes collected in spring (March-April) of the same year. In total, 332 prepubertal Sarda sheep were slaughtered and $7.5 \pm 1.56$ oocytes per animal were obtained for this study. The collection of oocytes and their subsequent maturation was carried out as previously described [21,23]. Briefly, ovaries collection from prepubertal ewes slaughtered for commercial purpose (30-40 days old; weight of 
8-10 Kg; not weaned) was performed over 1-2 h. Cumulus oocyte complexes (COCs) were selected according to morphological standard (4-10 layers of granulosa cells, uniform cytoplasm homogenous distribution of lipid droplets) and matured in vitro in TCM 199 with supplements heat-treated estrous sheep serum (10\%), Follicle-Stimulating Hormone (FSH; $1 \mathrm{IU} / \mathrm{mL})$, Luteinizing Hormone (LH; $1 \mathrm{IU} / \mathrm{mL})$, cysteamine (100 mM), and pyruvate $(8 \mathrm{mg} / \mathrm{mL})$. Thirty-five COCs were transferred to $600 \mu \mathrm{L}$ of maturation medium in fourwell Petri dishes (Nunclon, Nalge Nunc International, Denmark) and cultured in standard conditions ( $22 \mathrm{~h}$ in $5 \% \mathrm{CO}_{2}$ in air at $39{ }^{\circ} \mathrm{C}$ ). Following in vitro maturation, the COCs were mechanically denuded of cumulus cells and only those at metaphase II (MII) were selected and randomly assigned to the analyses.

\subsection{Determination of Oocytes Developmental Competence}

In vitro matured oocytes were fertilized with frozen/thawed spermatozoa from the same ejaculate of a single ram. The in vitro fertilization procedures (IVF) were conducted as previously described in standard conditions [14]. Briefly, cryopreserved semen was obtained from rams with proven fertility. The fertilization medium was composed of synthetic oviductal fluid (SOF) supplemented with $2 \%$ heat-treated estrous sheep serum, $10 \mu \mathrm{g} / \mathrm{mL}$ heparin, and $1 \mu \mathrm{g} / \mathrm{mL}$ hypoutarine. The motile and capacitated sperm fraction was selected by swim-up after incubation for $15 \mathrm{~min}$ at $39{ }^{\circ} \mathrm{C}$ and in $5 \% \mathrm{CO}_{2}, 5 \% \mathrm{O}_{2}$, and $90 \% \mathrm{~N}_{2}$ atmosphere. Swim-up-derived spermatozoa were co-incubated with in vitro matured oocytes at $39{ }^{\circ} \mathrm{C}$ and in $5 \% \mathrm{CO}_{2}, 5 \% \mathrm{O}_{2}$, and $90 \% \mathrm{~N}_{2}$ in a maximum minimum atmosphere. After $22 \mathrm{~h}$ of fertilization (hpf), the presumptive zygotes were transferred in a SOF medium with bovine serum albumin (BSA $4 \mathrm{mg} / \mathrm{mL}$ ) and essential and non-essential amino acids at oviductal concentration [25] and kept at $39^{\circ} \mathrm{C}, 5 \% \mathrm{O}_{2}, 5 \% \mathrm{CO}_{2}$ (i.e., the maximum humidified atmosphere). The number of embryos showing the first mitotic division at 22, 26, and $32 \mathrm{hpf}$ was recorded. Newly formed expanded blastocysts were recorded every day starting from the sixth until the ninth day post-fertilization (dpf).

\subsection{Evaluation of Mitochondrial Activity and Reactive Oxygen Species (ROS) Intracellular Level}

In vitro matured lamb oocytes were subjected to a simultaneous triple staining. First, oocytes were incubated in Phosphate Buffered Saline supplemented with $20 \% \mathrm{Fe}$ tal Calf Serum (PBS/20\%FCS) for $30 \mathrm{~min}$ at $38.5^{\circ} \mathrm{C}$ with Mito-Tracker Red CM- $\mathrm{H}_{2}$ XRos (500 nM; MT-Red, Molecular Probes, Inc., Eugene, OR, USA), a mitochondrial-specific fluorescent and cell-permeant probe. Subsequently, after being washed three times in PBS/0.1\%PVA, the oocytes were incubated for $20 \mathrm{~min}$ in the same medium with 20, 70-dichlorodihydrofluorescein diacetate (5 mM; $\mathrm{H}_{2}$ DCF-DA, Molecular Probe, Eugene, OR, USA), a reactive oxygen species (ROS) active molecular probe. Finally, the oocytes were counterstained with Hoechst 33342 in order to stain the chromosomes. After exposure to probes, the oocytes were washed three times in fresh PBS/0.1\%PVA and fixed in $2.5 \%$ glutaraldehyde/PBS for at least $15 \mathrm{~min}$. After fixation, the oocytes were prepared for the evaluation by using a confocal microscopy (Leica TCS SP5 CLSM with Leica LAS lite 170 Image software, Wetzlar, Germany). For mitochondrial evaluation, samples were observed with a multiphoton laser to detect MitoTracker Red CM- $\mathrm{H}_{2}$ XRos (ex: 579 nm; em: $599 \mathrm{~nm}$ ). An argon ions laser ray at $488 \mathrm{~nm}$ and the B-2 A filter (495 $\mathrm{nm}$ exposure and $519 \mathrm{~nm}$ emission) were used to point out the DCF [14].

\subsection{Tubulin Immunofluorescence and Confocal Microscope Evaluation}

In order to evaluate tyrosinated $\alpha$-tubulin (Tyr-T) and acetylated $\alpha$-tubulin (Ac-T) by immunofluorescence, IVM oocytes were fixed in PBS/4\% Paraformaldehyde solution and processed following the methodology illustrated previously $[21,23,26]$. In brief, the oocytes were processed through serial incubations $\left(1 \mathrm{~h}\right.$ per antibody at $\left.37^{\circ} \mathrm{C}\right)$ with the following primary antibodies: anti-Tyr-T (monoclonal, clone TUB-1A2, 1:1000) and antiAc-T (monoclonal, clone 6-11B-1, 1:1000). After rinsing with PBS/2\%FCS, the cells were incubated with secondary anti-mouse fluorescein isothiocyanate-conjugated antibodies 
(FITC-AlexaFluor 488, Thermo Fisher Scientific, Waltham, MA, USA), then washed three times, counterstained with Hoechst 33342, and mounted on a slide for immunostaining evaluation. The analysis of immunolabeled sections were performed with a confocal laser scanning microscope from Leica (TCS SP5 DMI 6000CS, Leica Microsystems GmbH, Wetzlar, Germany), equipped with $\mathrm{Ar} / \mathrm{He} / \mathrm{Ne}$ lasers, using a 40/60 X oil objective following the procedures standardized by Gadau $[26,27]$. Briefly, the sections were analyzed by sequential excitation of the two fluorochromes used (Hoechst 33342 and FITC 488), and parameters related to fluorescence intensity were maintained at constant values during all image acquisitions. Quantitative analysis of fluorescence intensity was performed using the Leica LAS AF Lite image analysis software package (Leica Microsystems $\mathrm{GmbH}$, Wetzlar, Germany).

\subsection{Statistical Analysis}

For the statistical analysis, the variables used were mitochondrial activity, ROS intracellular level, Tyr-T, and Ac-T fluorescence intensity. For each variable, the difference between spring and autumn was evaluated by ANOVA one-way Analysis of Variance after analysis for homogeneity of variance by Levene's test. The normal distribution of data was investigated by the Kolmogorov-Smirnov normality test, as most of the data were not normally distributed and data were log-transformed. All results were expressed as a mean \pm mean standard error (S.E.M.). Differences in developmental competence of prepubertal ovine oocyte collected during spring and autumn after in vitro maturation were analyzed using the chi square test $\left(\chi^{2}\right)$. Statistical analyses were performed using the statistical software Minitab ${ }^{\circledR} 17.1$ (2017 Minitab Inc., Coventry, UK) and a probability of $p \leq 0.05$ was considered the minimum level of significance.

\section{Results}

\subsection{Evaluation of Oocyte Developmental Competence}

Data regarding the oocyte developmental competence are shown in Table 1. The total cleavage rate was significantly lower in oocytes collected in autumn compared with oocytes collected in spring $(74.4 \%$ vs. $80.1 \%$, respectively; $p<0.01)$. No differences were observed in the cleavage of inseminated oocytes collected in spring and autumn at the different interval times post-fertilization (22-26-32 h).

Table 1. Developmental competence of prepubertal ovine oocytes collected during spring and autumn.

\begin{tabular}{|c|c|c|c|c|c|c|c|c|c|c|}
\hline \multirow{2}{*}{ Season } & \multirow{2}{*}{$\begin{array}{l}\text { No. of } \\
\text { Collected } \\
\text { Oocytes }\end{array}$} & \multirow{2}{*}{$\begin{array}{l}\text { In Vitro Matured } \\
\text { and Inseminated } \\
\text { Oocytes (\%) }\end{array}$} & \multicolumn{3}{|c|}{ Cleavage (\%) } & \multicolumn{5}{|c|}{ Blastocyst (\%) } \\
\hline & & & & & Tot* & $7 \mathrm{dpf}$ & $8 \mathrm{dpf}$ & $9 \mathrm{dpf}$ & Tot $* *$ & Tot $* * *$ \\
\hline Autumn & 898 & $\begin{array}{c}624 \\
(69.5)\end{array}$ & $\begin{array}{c}351 \\
(75.6)\end{array}$ & $\begin{array}{c}113 \\
(24.4)\end{array}$ & $\begin{array}{l}464^{a} \\
(74.4)\end{array}$ & $\begin{array}{c}8^{a} \\
(13.8)\end{array}$ & $\begin{array}{c}44^{\mathrm{a}} \\
(75.9)\end{array}$ & $\begin{array}{c}6 \\
(10.3)\end{array}$ & $\begin{array}{c}58^{\mathrm{a}} \\
(12.5)\end{array}$ & $\begin{array}{l}58^{a} \\
(6.5)\end{array}$ \\
\hline Spring & 1373 & $\begin{array}{c}1005 \\
(73.2)\end{array}$ & $\begin{array}{c}575 \\
(71.4)\end{array}$ & $\begin{array}{c}230 \\
(28.6)\end{array}$ & $\begin{array}{l}805^{b} \\
(80.1)\end{array}$ & $\begin{array}{c}74^{\mathrm{b}} \\
(46.5)\end{array}$ & $\begin{array}{c}71^{\mathrm{b}} \\
(44.6)\end{array}$ & $\begin{array}{c}14 \\
(8.8)\end{array}$ & $\begin{array}{l}159^{b} \\
(19.8)\end{array}$ & $\begin{array}{l}159^{b} \\
(11.6)\end{array}$ \\
\hline
\end{tabular}

* The percentage of total cleavage is calculated on the number of fertilized oocytes, while the cleavage during the two interval postfertilization is calculated on total cleaved oocytes. ${ }^{* *}$ The percentage of total blastocysts is calculated on the number of total cleaved oocytes, while distribution across the post-fertilization days is calculated as rate on the total blastocysts; *** The percentage of total blastocysts is calculated on the number of collected oocytes. hpf, hours post-fertilization; dpf, days post-fertilization. Within the same column, different letters indicate statistical differences, $p<0.01$ (Chi-square test).

Data on blastocyst production confirmed the cleavage data, with a lower rate of blastocysts derived from the autumn group compared with those derived from the spring group $(12.5 \%$ vs. $19.8 \%$ respectively; $p<0.01)$. The distribution of blastocysts according to the day post-fertilization (dpf) culture in which they appeared, showed a delay of development in the autumn group. In the spring group, in fact, blastocyst production on the seventh dpf was significantly higher $(46.5 \%)$ compared to autumn $(13.8 \% ; p<0.01)$. After eight days of culture, the blastocysts rate was higher in the autumn group compared 
with the spring group $(75.9 \%$ vs. $44.6 \%$ respectively; $p<0.01)$. No differences in blastocyst production were registered between the two groups after the ninth dpf.

\subsection{Evaluation of Mitochondrial Activity and ROS Intracellular Level}

Fluorescence intensity data (measured as relative intensity (rfu), after incubation with the Mitotracker-Red probe and ROS sensitive fluorescent staining in five replicates, showed statistical differences between the two experimental groups. Mitochondrial activity was significantly higher $(p<0.05)$ in oocytes collected in spring compared with those collected in autumn ( $35.31 \pm 14.17$ vs. $29.07 \pm 13.69$ rfu respectively) while, on the contrary, ROS intracellular levels were significantly lower $(p<0.05)$ in oocytes collected in spring compared with oocytes collected in autumn $(15.31 \pm 9.29$ vs. $17.87 \pm 6.78$ respectively; Figure 1).

\section{Seasonal fluorescence intensity of mitochondrial activity and ROS intracellular level}

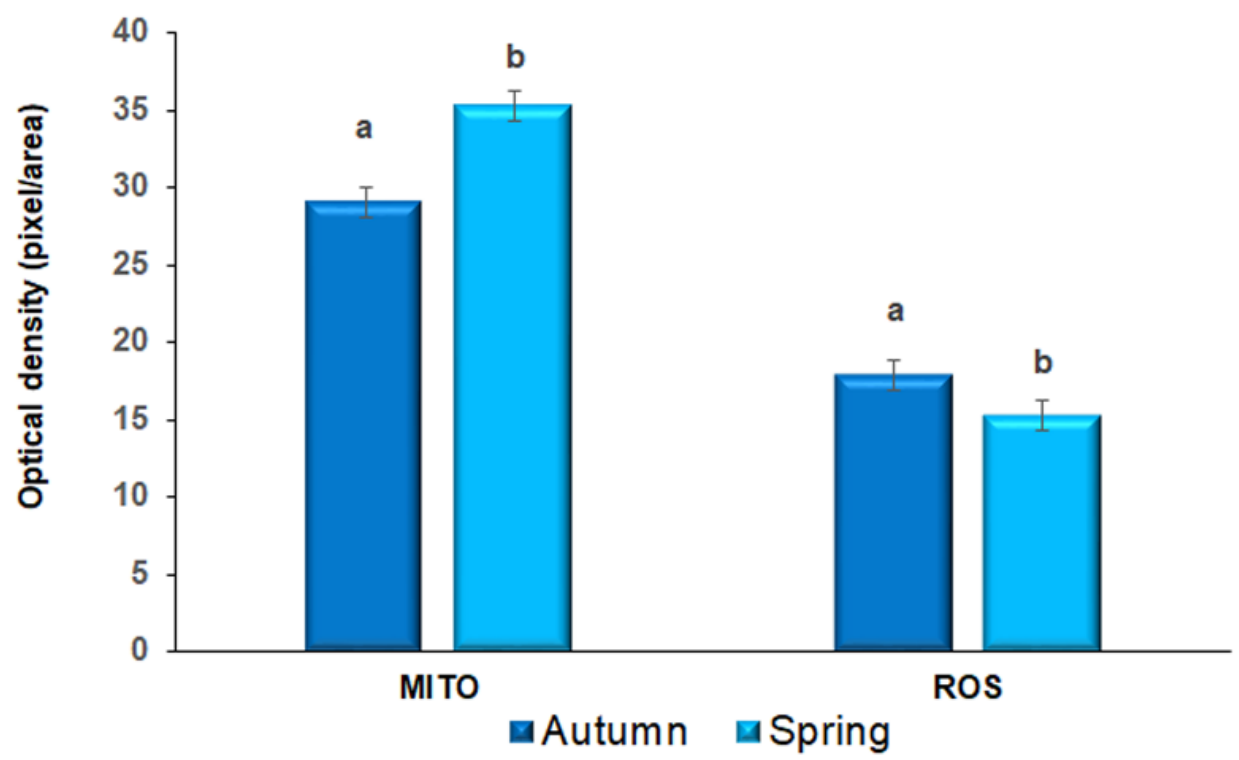

Figure 1. Quantification of fluorescence intensity after incubation with Mitotracker-Red stain (MtRed) and $\mathrm{H}_{2}$ DCF-DA probe (reactive oxygen species, ROS) in metaphase II prepubertal ovine oocytes collected during autumn and spring. Values are expressed as arbitrary units (Mean \pm mean standard error). Different lower-case letters indicate statistical difference into mitochondrial fluorescence intensity $(p<0.05$ ANOVA). Different lower-case letters indicate statistical difference into DCHFDA fluorescence intensity ( $p<0.05$ ANOVA).

\subsection{Evaluation of Tubulin Assessment}

Immunofluorescence for tyrosinated and acetylated $\alpha$-tubulin, evaluated in five replicates displayed a clearly visible signal emission in the meiotic spindle of both spring and autumn prepubertal ovine oocytes. The signal intensity of both tyrosinated and acetylated $\alpha$-tubulin was significantly higher $(p<0.01)$ in oocytes collected in spring than in oocytes collected in autumn. As shown in Figure 2a the levels of tyrosinated $\alpha$-tubulin were $55.6 \pm 4.6$ vs. $18.7 \pm 2.2 \mathrm{rfu}$ in oocytes collected in spring and autumn, respectively. Instead, levels of acetylated $\alpha$-tubulin, displayed in Figure $2 \mathrm{~b}$, were $46.8 \pm 3.1$ vs. $7.6 \pm 2.2 \mathrm{rfu}$ in oocytes collected in spring and autumn, respectively. Moreover, considering the fluorescence intensity of the two diverse tubulin PTMs within each experimental group, in the spring group no differences were shown between tyrosinated and acetylated $\alpha$-tubulin fluorescence intensity ( $47.8 \pm 3.1$ vs. $55.6 \pm 4.6 \mathrm{rfu}$ in spring and autumn oocytes, respectively; Figure $3 \mathrm{~A})$. On the contrary, in the autumn group the fluorescence intensity of acetylated 
$\alpha$-tubulin was significantly higher compared with tyrosinated $\alpha$-tubulin $(18.7 \pm 2.2$ vs. $7.6 \pm 2.2 \mathrm{rfu}$ in spring and autumn groups, respectively; $p<0.01$; Figure $3 \mathrm{~B}$ ).
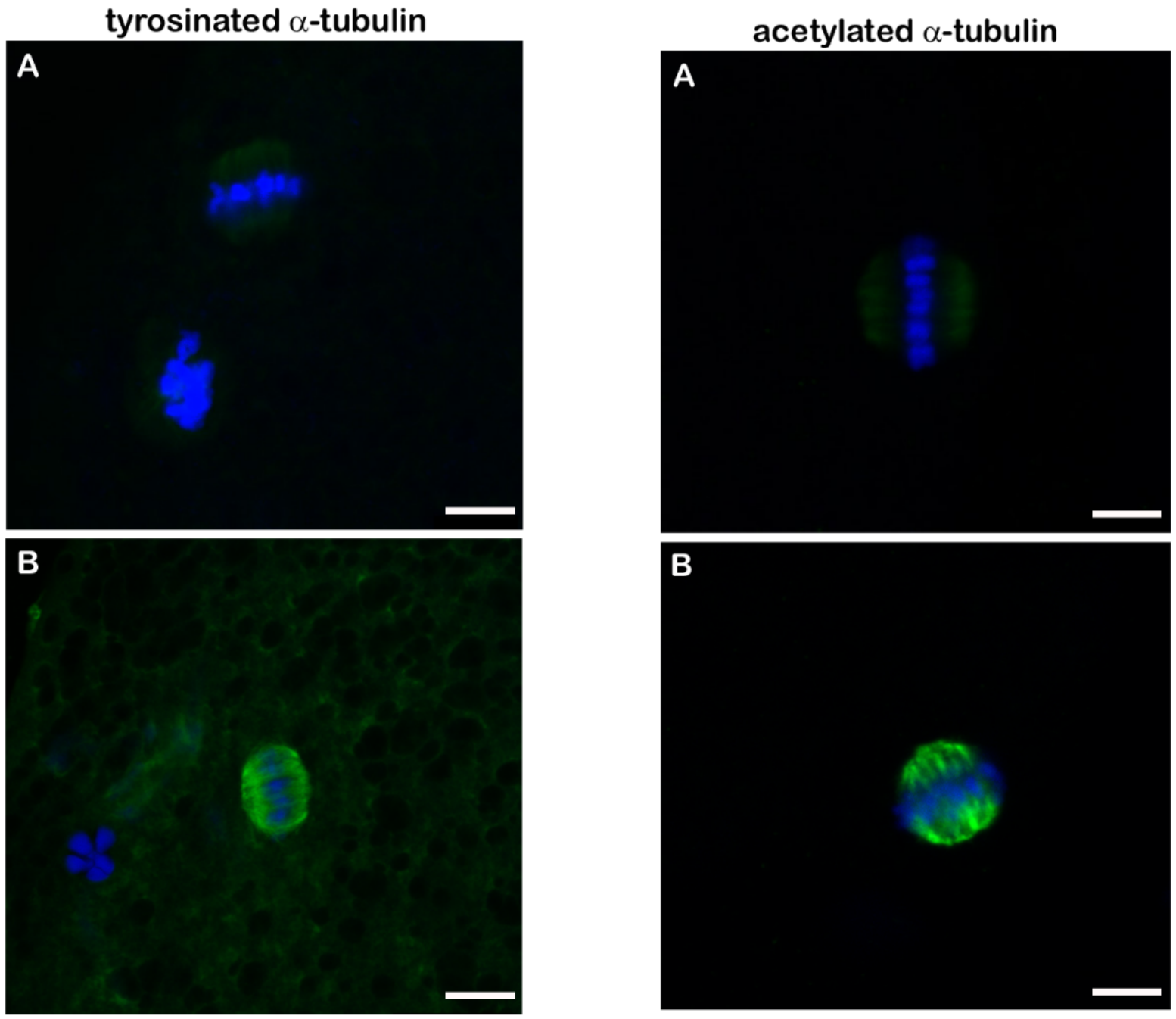

Seasonal fluorescence intensity of tyrosinated a-tubulin

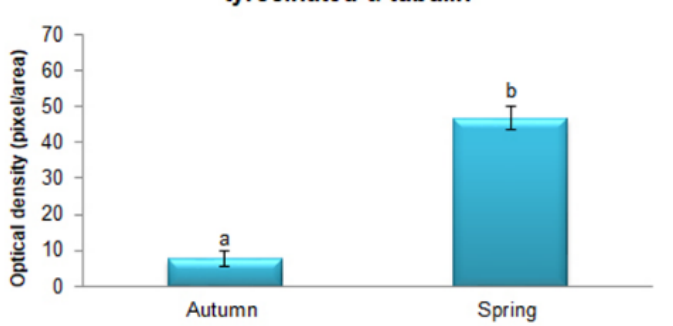

(a)

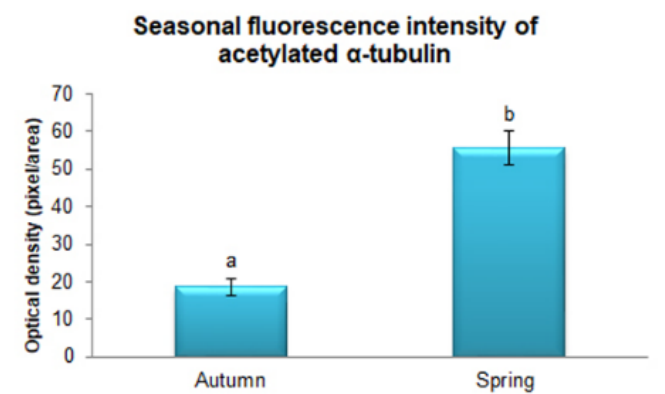

(b)

Figure 2. Quantification of fluorescence intensity of tyrosinated (a) and acetylated (b) $\alpha$-tubulin in metaphase II prepubertal ovine oocytes collected during Autumn (A) and Spring (B). Values are expressed as arbitrary units (Mean \pm mean standard error). Different lower-case letters indicate statistical difference in tyrosinated $\alpha$-tubulin fluorescence intensity in autumn and spring ( $p<0.01$ ANOVA). 

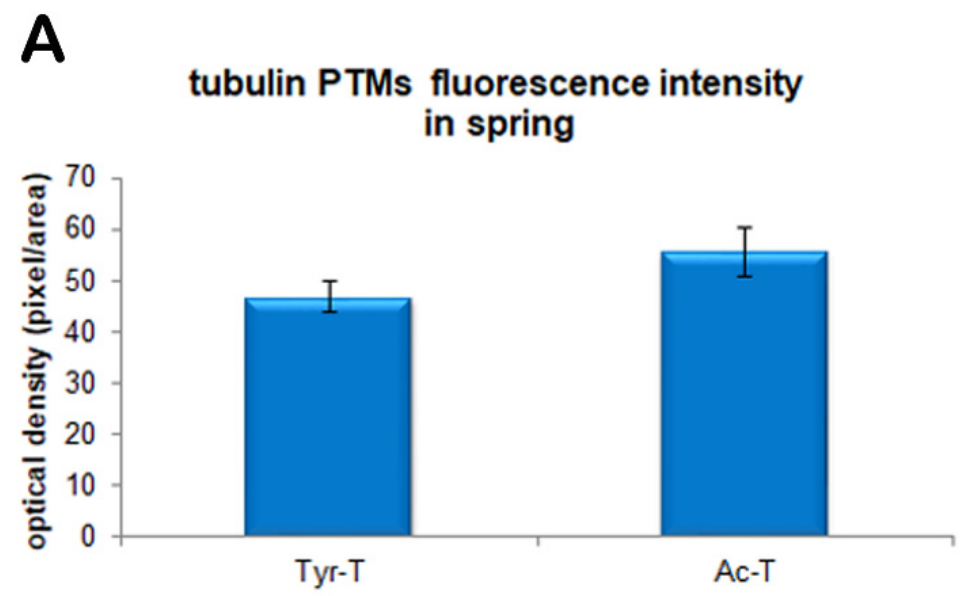

\section{B tubulin PTMs fluorescence intensity in autumn}

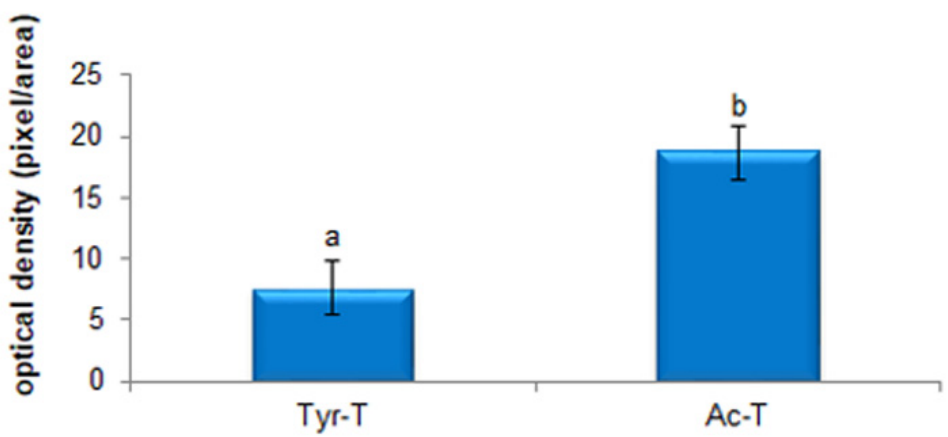

Figure 3. Quantification of fluorescence intensity for tyrosinated and acetylated $\alpha$-tubulin in MII prepubertal ovine oocyte collected in autumn (A) and spring (B). Values are expressed as arbitrary units (Mean \pm mean standard error). Different lower-case letters indicate statistical difference between tyrosinated and acetylated $\alpha$-tubulin fluorescence intensity in autumn (A) and spring (B) metaphase II prepubertal ovine oocytes ( $p<0.01$ ANOVA).

\section{Discussion}

The aim of the present study was to determine the effect of seasons on the oocyte quality of ewe lambs collected at the slaughterhouse during two different periods of the year (autumn and spring). Considering the pivotal role of oocytes in female reproduction, different authors have studied the role of seasonal variations in the developmental capacity of the oocyte and natural fertility in different seasonal breeder species such as sheep [28], goats [29], horses [30,31], and buffalo [5]. In sheep, the positive impact of the breeding season on oocyte quality and reproductive performance has been related to the higher number of recovered oocytes [32,33], higher cleavage rate [34], and higher blastocyst production [9]. Instead, the efficiency of ovum recovery procedures applied in the nonbreeding season is affected in terms of elevated percentage of unfertilized oocytes and poor embryo viability, as well as a reduced cleavage rate after IVF of ovulated oocyte [35]. In adults, this is explained by physiological and hormonal changes and characteristics of the reproductive season that induce optimal follicular development and, hence, an increased oocyte quality [36,37]. In adult sheep, the higher cleavage [34] and blastocyst rate [9] of oocytes collected during the breeding season (rather than in anoestrous) is relative to the higher developmental competence of oocytes recovered during a decreasing photoperiod, when short days stimulate sexual activity.

With respect to oocytes from prepubertal animals, the effect of season still remains to be explored, However, our data has shown that in our geographical conditions the 
season may affect the quality of ovine oocytes from young donors. In prepubertal goats, it has been shown that the season affects the fatty acid composition in follicular fluid and, consequently, oocyte competence [38]. In this study, it has been observed that the lowest blastocyst production after IVF and parthenogenetic activation procedures are in autumn compared to winter and spring seasons, correlated with a lower n6: n3 PUFA ratio obtained in winter than in autumn. Furthermore, other authors have reported a higher cleavage rate in winter compared with autumn using oocytes from four to eight week-old lambs [39]. Our data are quite in line with results reported by these authors. The worst performances were in fact also recorded by our research group during autumn, even if compared only to spring due to the lack of slaughtered animals in winter for commercial reasons.

Despite the fact that oocytes collected during the two seasons reached metaphase II (Table 1) at the same rate, autumn oocytes showed a lower developmental competence compared to the spring group, meaning that the ability of the oocytes to reach meiotic maturation does not necessarily confirm the achievement of full developmental competence $[40,41]$. Indeed, lower cleavage and blastocysts rates were recorded in the autumn group and the lower developmental capacity of these oocytes was highlighted also in terms of the quality of produced embryos. The day of blastocyst appearance has been related to the embryo developmental potential [42]. In sheep, it has been demonstrated that earlier produced blastocysts show a higher viability and hatching rate after vitrification and warming. Thus, the days of blastocyst production reflect the quality of obtained embryos [43]. Early obtained blastocysts (seventh dpf) are numerically more elevated in the spring group, while in the autumn group the greatest number of blastocysts is obtained one day later with a delay of cell cycles during embryo culture [43]. It follows that reduced cleavage and blastocyst rates, and a subsequently reduced quality of produced embryos observed in the autumn group, could be related to a low quality of oocytes collected during this season compared with oocytes collected in spring.

Given that, as far as we know, the prepubertal endocrine environment is profoundly different than in adults due to the hypothalamic-pituitary-gonadal axis quiescent and minimal levels of sex steroids [44], we can speculate that season can induce local autocrine and paracrine changes, and may regulate follicular environment and, thus, oocyte quality in these young animals. Considering that the meiotic competence observed was similar in oocytes collected in spring and autumn, we can hypothesize that cytoplasmic competence is influenced by seasonal change. Indeed, an insufficient prepubertal oocyte capacitation during follicular growth induces reduced embryo quality and a failure of embryonic development $[45,46]$. In fact, the low quality of prepubertal oocyte cytoplasm has already been associated with an altered cytoplasmic molecular environment $[12,47,48]$. This finding was supported by our data on cytoplasmic mitochondrial activity and ROS intracellular levels. The regulation of intracellular redox potential in the oocyte is a crucial determinant of fertility and embryo development $[12,14]$. The presence of ROS within the cytoplasm of the oocyte is physiological, closely related to the oxidative metabolism, even though their effects are dose dependent. At low levels, ROS regulate specific cellular functions [49] while at high levels they produce oxidative stress on the cell resulting in molecular damage to DNA, proteins, and lipids [50]. Oxidative injury may induce the release of cytochrome c and other apoptogenic factors from mitochondria which eventually activate programmed cell death [51]. Oxidative stress has also been associated with impaired early development and fragmented embryos. In fact, the alteration of intracellular redox potential is associated with a reduction of mitochondrial activity and, as a consequence, negatively affects the bioenergetics status [50] decreasing ATP levels, compromising the progression of oocyte maturation and the development of preimplantation embryos [52,53]. Since mitochondria assume a vital role in the metabolism of energy-containing compounds in the ooplasm in order to provide ATP for fertilization and pre-implantation embryonic development, their role in ATP production is essential for oocyte quality [12]. In sheep oocytes, we demonstrated that high levels of mitochondrial activity and low ROS intracytoplasmic concentrations were related to greater developmental competence [14,43]. The present 
data evidenced a higher mitochondrial activity and a lower ROS level in spring oocytes compared to autumn ones, evidencing the improved quality of oocytes collected during spring season.

Even data resulting from the analysis of the post-translational modifications of tubulin would seem to confirm this hypothesis. The importance of the microtubular network in the oocyte is well known, as it is involved in the formation of the meiotic spindle, chromosome segregation, fertilization, and embryonic development [54,55]. The data resulting from the fluorescence analysis of tyrosinated and acetylated $\alpha$-tubulin revealed a different intensity pattern between the two seasonal periods examined, with a clear balance between the two PTMs in oocytes harvested during spring which could be considered a marker of a "highly competent system" [21]. This balance is the basis of the normal functionality of a meiotic spindle, a structure that must be equipped with dynamism and stability at the same time. It is well known that tyrosination is a typical modification of dynamic and unstable microtubules [56-58]. The latter move in the cell cytoplasm in search of their target, which in the case of the meiotic spindle are chromosomes [59,60]. After the search and capture phase, stabilization of microtubules through acetylation appears to be at the basis of normal chromosome alignment, and appears to consolidate once the microtubule contacts the kinetochore $[61,62]$. Furthermore, tubulin acetylation confers resistance to traction forces in those curved structures such as the meiotic spindle [63]. In the evaluation of the immunopositivity level of tubulin PTMs in autumn lamb oocytes, we can speculate that the balance between the stability and dynamism of the microtubule is lacking, since oocytes displayed higher levels of acetylated than tyrosinated tubulin. A higher immunopositivity of acetylated tubulin due to a predominant acetylation on the microtubules may lead to morphological alterations of the meiotic spindle and to alignment defects $[21,64]$. This imbalance in the composition of tubulin PTMs may be an additional factor causing poor developmental competence of lamb oocytes collected in the autumn period, as it would threat the intrinsic "dynamic stability" of the microtubules [65].

In addition, maternal stress and nutrition during pregnancy might influence the environment in the uterus and the development of fetal ovaries and/or oocyte development of the offspring. The semi-extensive farming system of dairy sheep in Mediterranean countries, as well as in Sardinia, is based mainly on pastures whose quantitative and qualitative availability is influenced by environmental conditions and by season $[66,67]$. In our latitude, in early spring from March to April, the highest quality of pasture can be found with a subsequent decrease in forage quality during the following months due to the fact that plants mature from the vegetative to the reproductive stage [68]. Several authors reported that seasonal, and consequently nutritional differences, in pastures influences sheep milk composition, milk yield [69-72], and also affects the carcass and meat quality of suckling lambs [73]. It appears that lambs born and slaughtered in spring have a high quantity and quality of milk available to them compared with those born and slaughtered in autumn. Inevitably, such more satisfactory energetic conditions positively affect the ovarian environment. These could be some of the reasons to explain why lambs born in autumn show a different ovarian status with less oocyte competence compared to oocytes collected in the spring season. Further studies are needed to elucidate mechanisms involved in the acquisition of prepubertal ovine oocyte quality in relation to the season.

\section{Conclusions}

Our data show that season may affect developmental competence, energetic status, and tubulin assessment of oocytes recovered from prepubertal ewes. Therefore, careful attention should be paid in choosing the period of the year for prepuberal ovine oocytes collection for in vitro embryo reproduction programs. 
Author Contributions: Conceptualization, E.S., S.D.G. and S.S.; methodology, E.S. and S.S.; validation, E.S., S.D.G. and S.S.; formal analysis, E.S., S.D.G., S.N., G.G.L. and S.S.; investigation, E.S., S.D.G. and S.S.; resources, S.D.G., S.N. and S.S.; data curation, E.S., S.D.G. and S.S.; writing-original draft preparation, E.S., S.D.G. and S.S.; writing-review and editing, E.S., S.D.G., S.N., G.G.L. and S.S.; supervision, S.S. All authors have read and agreed to the published version of the manuscript.

Funding: This research received no external funding.

Institutional Review Board Statement: This study was not conducted on experimental animals. The material used (ovaries of lambs) was collected post-mortem in the slaughterhouses. All aspects relating to animal welfare are the responsibility of the staff employed in slaughterhouses, according to the EU guidelines (Regulation of European Parliament and of the Council 853/2004; 627/2019; 1/2005; 1255/97). The ethics committee of our university has expressed a favorable opinion (Registration No. 56416/21).

Data Availability Statement: Data presented in this study are available on request from the corresponding author.

Conflicts of Interest: The authors declare no conflict of interest.

\section{References}

1. Wood, S.; Quinn, A.; Troupe, S.; Kingsland, C.; Lewis-Jones, I. Seasonal variation in assisted conception cycles and the influence of photoperiodism on outcome in in vitro fertilization cycles. Hum. Fertil. 2006, 9, 223-229. [CrossRef]

2. Tsutsui, K.; Ubuka, T. How to contribute to the progress of neuroendocrinology: Discovery of GnIH and progress of GnIH research. Front. Endocrinol. 2018, 9, 223. [CrossRef]

3. Nestor, C.C.; Bedenbaugh, M.N.; Hileman, S.M.; Coolen, L.M.; Lehman, M.N.; Goodman, R.L. Regulation of GnRH pulsatility in ewes. Reproduction 2018, 156, R83-R99. [CrossRef]

4. Robinson, T.J. Use of progestagen-impregnated sponges inserted intravaginally or subcutaneously for the control of the oestrous cycle in the sheep. Nature 1965, 206, 39-41. [CrossRef] [PubMed]

5. Gasparrini, B. Effects of reproductive season on embryo development in the buffalo. Reprod. Fertil. Dev. 2019, 31, 68-81. [CrossRef]

6. Rutledge, J.; Monson, R.; Northey, D.; Leibfried-Rutledge, M. Seasonality of cattle embryo production in a temperate region. Theriogenology 1999, 51, 330. [CrossRef]

7. Spindler, R.E.; Wildt, D.E. Circannual variations in intraovarian oocyte but not epididymal sperm quality in the domestic cat. Biol. Reprod. 1999, 61, 188-194. [CrossRef] [PubMed]

8. Zheng, P.; Si, W.; Wang, H.; Zou, R.; Bavister, B.D.; Ji, W. Effect of age and breeding season on the developmental capacity of oocytes from unstimulated and Follicle-Stimulating Hormone-stimulated rhesus monkeys. Biol. Reprod. 2001, 64, 1417-1421. [CrossRef] [PubMed]

9. Mara, L.; Sanna, D.; Casu, S.; Dattena, M.; Muñoz, I.M.M. Blastocyst rate of in vitro embryo production in sheep is affected by season. Zygote 2014, 22, 366-371. [CrossRef] [PubMed]

10. Krisher, R.L. The effect of oocyte quality on development. J. Anim. Sci. 2004, 82, E14-E23.

11. Sirard, M.A.; Richard, F.; Blondin, P.; Robert, C. Contribution of the oocyte to embryo quality. Theriogenology 2006, 65, 126-136. [CrossRef] [PubMed]

12. Leoni, G.G.; Palmerini, M.G.; Satta, V.; Succu, S.; Pasciu, V.; Zinellu, A.; Carru, C.; Macchiarelli, G.; Nottola, S.A.; Naitana, S.; et al. Differences in the kinetic of the first meiotic division and in active mitochondrial distribution between prepubertal and adult oocytes mirror differences in their developmental competence in a sheep model. PLoS ONE 2015, 10, e0124911. [CrossRef] [PubMed]

13. Nagai, S.; Mabuchi, T.; Hirata, S.; Shoda, T.; Kasai, T.; Yokota, S.; Shitara, H.; Yonekawa, H.; Hoshi, K. Correlation of abnormal mitochondrial distribution in mouse oocytes with reduced developmental competence. Tohoku J. Exp. Med. 2006, 210, 137-144. [CrossRef] [PubMed]

14. Succu, S.; Gadau, S.D.; Serra, E.; Zinellu, A.; Carru, C.; Porcu, C.; Naitana, S.; Berlinguer, F.; Leoni, G.G. A recovery time after warming restores mitochondrial function and improves developmental competence of vitrified ovine oocytes. Theriogenology 2018, 110, 18-26. [CrossRef] [PubMed]

15. Blerkom, J. Van Mitochondrial function in the human oocyte and embryo and their role in developmental competence. Mitochondrion 2011, 11, 797-813. [CrossRef]

16. Tamura, H.; Takasaki, A.; Miwa, I.; Taniguchi, K.; Maekawa, R.; Asada, H.; Taketani, T.; Matsuoka, A.; Yamagata, Y.; Shimamura, K.; et al. Oxidative stress impairs oocyte quality and melatonin protects oocytes from free radical damage and improves fertilization rate. J. Pineal Res. 2008, 44, 280-287. [CrossRef] [PubMed]

17. Lord, T.; Nixon, B.; Jones, K.T.; Aitken, R.J. Melatonin prevents postovulatory oocyte aging in the mouse and extends the window for optimal fertilization in vitro. Biol. Reprod. 2013, 88, 67. [CrossRef]

18. Wang, T.; Lessman, C.A. Isoforms of soluble $\alpha$-tubulin in oocytes and brain of the frog (genus Rana): Changes during oocyte maturation. Cell. Mol. Life Sci. 2002, 59, 2216-2223. [CrossRef] 
19. Combelles, C.M.H.; Albertini, D.F. Microtubule patterning during meiotic maturation in mouse oocytes is determined by cell cycle-specific sorting and redistribution of $\gamma$-tubulin. Dev. Biol. 2001, 239, 281-294. [CrossRef]

20. Li, R.; Albertini, D.F. The road to maturation: Somatic cell interaction and self-organization of the mammalian oocyte. Nat. Rev. Mol. Cell Biol. 2013, 14, 141-152. [CrossRef] [PubMed]

21. Serra, E.; Succu, S.; Berlinguer, F.; Porcu, C.; Leoni, G.G.; Naitana, S.; Gadau, S.D. Tubulin posttranslational modifications in in vitro matured prepubertal and adult ovine oocytes. Theriogenology 2018, 114, 237-243. [CrossRef]

22. Fukushima, N.; Furuta, D.; Hidaka, Y.; Moriyama, R.; Tsujiuchi, T. Post-translational modifications of tubulin in the nervous system. J. Neurochem. 2009, 109, 683-693. [CrossRef]

23. Serra, E.; Gadau, S.D.; Berlinguer, F.; Naitana, S.; Succu, S. Morphological features and microtubular changes in vitrified ovine oocytes. Theriogenology 2020, 148, 216-224. [CrossRef]

24. Ledda, S.; Bogliolo, L.; Calvia, P.; Leoni, G.; Naitana, S. Meiotic progression and developmental competence of oocytes collected from juvenile and adult ewes. J. Reprod. Fertil. 1997, 109, 73-78. [CrossRef]

25. Walker, S.K.; Hill, J.L.; Kleemann, D.O.; Nancarrow, C.D. Development of ovine embryos in synthetic oviductal fluid containing amino acids at oviductal fluid concentrations. Biol. Reprod. 1996, 55, 703-708. [CrossRef]

26. Gadau, S.D. Tubulin post-translational modifications in developing dog primary neurons obtained with methods according to the 3Rs principles. Res. Vet. Sci. 2019, 122, 56-63. [CrossRef]

27. Gadau, S.D. Morphological and quantitative analysis on $\alpha$-tubulin modifications in glioblastoma cells. Neurosci. Lett. 2018, 687, 111-118. [CrossRef] [PubMed]

28. Rosa, H.J.D.; Bryant, M.J. Seasonality of reproduction in sheep. Small Rumin. Res. 2003, 48, 155-171. [CrossRef]

29. Leboeuf, B.; Delgadillo, J.A.; Manfredi, E.; Piacère, A.; Clément, V.; Martin, P.; Pellicer, M.; Boué, P.; Cremoux, R. De Management of Goat Reproduction and Insemination for Genetic Improvement in France. Reprod. Domest. Anim. 2008, 43, 379-385. [CrossRef]

30. Colleoni, S.; Luciano, A.M.; Gandolfi, F. Cumulus-oocyte communications in the horse: Role of the breeding season and of the maturation medium. Reprod. Domest. Anim. 2004, 39, 70-75. [CrossRef] [PubMed]

31. Hinrichs, K.; Schmidt, A.L. Meiotic competence in horse oocytes: Interactions among chromatin configuration, follicle size, cumulus morphology, and season. Biol. Reprod. 2000, 62, 1402-1408. [CrossRef] [PubMed]

32. Davachi, N.D.; Shahneh, A.Z.; Kohram, H.; Zhandi, M.; Dashti, S.; Shamsi, H.; Moghadam, R. In vitro ovine embryo production: The study of seasonal and oocyte recovery method effects. Iran. Red Crescent Med. J. 2014, 16, e20749.

33. Ahmadi, E.; Nazari, H.; Hossini-Fahraji, H. Low developmental competence and high tolerance to thermal stress of ovine oocytes in the warm compared with the cold season. Trop. Anim. Health Prod. 2019, 51, 1611-1618. [CrossRef]

34. Stenbak, T.K.; Redmer, D.A.; Berginski, H.R.; Erickson, A.S.; Navanukraw, C.; Toutges, M.J.; Bilski, J.J.; Kirsch, J.D.; Kraft, K.C.; Reynolds, L.P.; et al. Effects of follicle stimulating hormone (FSH) on follicular development, oocyte retrieval, and in vitro fertilization (IVF) in ewes during breeding season and seasonal anestrus. Theriogenology 2001, 56, 51-64. [CrossRef]

35. Mitchell, L.M.; Mylne, M.J.A.; Hunton, J.; Matthews, K.; McEvoy, T.G.; Robinson, J.J.; Dingwall, W.S. Ovum recovery from ewes during the peak breeding season and transition to anoestrus. BSAP Occas. Publ. 2004, 30, 327-329. [CrossRef]

36. Berlinguer, F.; Gonzalez-Bulnes, A.; Succu, S.; Leoni, G.; Mossa, F.; Bebbere, D.; Ariznavarreta, C.; Tresguerres, J.A.F.; Veiga-Lopez, A.; Naitana, S. Effects of progestagens on follicular growth and oocyte developmental competence in FSH-treated ewes. Domest. Anim. Endocrinol. 2007, 32, 303-314. [CrossRef]

37. Gonzalez-Bulnes, A.; Veiga-Lopez, A.; Garcia, P.; Garcia-Garcia, R.M.; Ariznavarreta, C.; Sanchez, M.A.; Tresguerres, J.A.F.; Cocero, M.J.; Flores, J.M. Effects of progestagens and prostaglandin analogues on ovarian function and embryo viability in sheep. Theriogenology 2005, 63, 2523-2534. [CrossRef]

38. Catala, M.G.; Roura, M.; Soto-Heras, S.; Menéndez, I.; Contreras-Solis, I.; Paramio, M.T.; Izquierdo, D. Effect of season on intrafollicular fatty acid concentrations and embryo production after in vitro fertilization and parthenogenic activation of prepubertal goat oocytes. Small Rumin. Res. 2018, 168, 82-86. [CrossRef]

39. Gou, K.M.; Guan, H.; Bai, J.H.; Cui, X.H.; Wu, Z.F.; Yan, F.X.; An, X.R. Field evaluation of juvenile in vitro embryo transfer (JIVET) in sheep. Anim. Reprod. Sci. 2009, 112, 316-324. [CrossRef] [PubMed]

40. Brevini Gandolfi, T.A.L.; Gandolfi, F. The maternal legacy to the embryo: Cytoplasmic components and their effects on early development. Theriogenology 2001, 55, 1255-1276. [CrossRef]

41. Sirard, M.A. Resumption of meiosis: Mechanism involved in meiotic progression and its relation with developmental competence. Theriogenology 2001, 55, 1241-1254. [CrossRef]

42. Soom, A.V.; Ysebaert, M.T.; Kruif, A. De Relationship between timing of development, morula morphology, and cell allocation to inner cell mass and trophectoderm in in vitro-produced bovine embryos. Mol. Reprod. Dev. 1997, 47, 47-56. [CrossRef]

43. Leoni, G.G.; Succu, S.; Berlinguer, F.; Rosati, I.; Bebbere, D.; Bogliolo, L.; Ledda, S.; Naitana, S. Delay on the in vitro kinetic development of prepubertal ovine embryos. Anim. Reprod. Sci. 2006, 92, 373-383. [CrossRef]

44. Torres-Rovira, L.; Gonzalez-Bulnes, A.; Succu, S.; Spezzigu, A.; Manca, M.E.; Leoni, G.G.; Sanna, M.; Pirino, S.; Gallus, M.; Naitana, S.; et al. Predictive value of antral follicle count and anti-Müllerian hormone for follicle and oocyte developmental competence during the early prepubertal period in a sheep model. Reprod. Fertil. Dev. 2014, 26, 1094-1106. [CrossRef]

45. Hyttel, P.; Fair, T.; Callesen, H.; Greve, T. Oocyte growth, capacitation and final maturation in cattle. Theriogenology 1997, 47, $23-32$. [CrossRef] 
46. Fulka, J.; First, N.L.; Moor, R.M. Nuclear and cytoplasmic determinants involved in the regulation of mammalian oocyte maturation. Mol. Hum. Reprod. 1998, 4, 41-49. [CrossRef]

47. Leoni, G.G.; Bebbere, D.; Succu, S.; Berlinguer, F.; Mossa, F.; Galioto, M.; Bogliolo, L.; Ledda, S.; Naitana, S. Relations between relative mRNA abundance and developmental competence of ovine oocytes. Mol. Reprod. Dev. 2007, 74, 249-257. [CrossRef]

48. Bebbere, D.; Bogliolo, L.; Ariu, F.; Fois, S.; Leoni, G.G.; Succu, S.; Berlinguer, F.; Ledda, S. Different temporal gene expression patterns for ovine pre-implantation embryos produced by parthenogenesis or in vitro fertilization. Theriogenology 2010, 74, 712-723. [CrossRef] [PubMed]

49. Dalton, T.P.; Shertzer, H.G.; Puga, A. Regulation of gene expression by reactive oxygen. Annu. Rev. Pharmacol. Toxicol. 1999, 39, 67-101. [CrossRef] [PubMed]

50. Tatone, C.; Emidio, G.D.; Vento, M.; Ciriminna, R.; Artini, P.G. Cryopreservation and oxidative stress in reproductive cells. Gynecol. Endocrinol. 2010, 26, 563-567. [CrossRef]

51. Orrenius, S.; Gogvadze, V.; Zhivotovsky, B. Mitochondrial oxidative stress: Implications for cell death. Annu. Rev. Pharmacol. Toxicol. 2007, 47, 143-183. [CrossRef]

52. Blerkom, J.V.; Davis, P.W.; Lee, J. Fertilization and early embryolgoy: ATP content of human oocytes and developmental potential and outcome after in-vitro fertilization and embryo transfer. Hum. Reprod. 1995, 10, 415-424. [CrossRef]

53. Zeng, H.T.; Ren, Z.; Yeung, W.S.B.; Shu, Y.M.; Xu, Y.W.; Zhuang, G.L.; Liang, X.Y. Low mitochondrial DNA and ATP contents contribute to the absence of birefringent spindle imaged with PolScope in in vitro matured human oocytes. Hum. Reprod. 2007, 22, 1681-1686. [CrossRef] [PubMed]

54. Ai, J.S.; Wang, Q.; Li, M.; Shi, L.H.; Ola, S.I.; Xiong, B.; Yin, S.; Chen, D.Y.; Sun, Q.Y. Roles of microtubules and microfilaments in spindle movements during rat oocyte meiosis. J. Reprod. Dev. 2008, 54, 391-396. [CrossRef]

55. Schatten, H.; Sun, Q.Y. Centrosome dynamics during mammalian oocyte maturation with a focus on meiotic spindle formation. Mol. Reprod. Dev. 2011, 78, 757-768. [CrossRef]

56. Gundersen, G.G.; Bulinski, J.C. Distribution of tyrosinated and nontyrosinated $\alpha$-tubulin during mitosis. J. Cell Biol. 1986, 102, 1118-1126. [CrossRef]

57. Viklický, V.; Dráber, P.; Hašek, J.; Bártek, J. Production and characterization of a monoclonal antitubulin antibody. Cell Biol. Int. Rep. 1982, 6, 725-731. [CrossRef]

58. Schaletzky, J.; Rape, M. Getting a Grip on Microtubules. Cell 2016, 164, 836-837. [CrossRef]

59. Pavin, N.; Tolić-Nørrelykke, I.M. Swinging a sword: How microtubules search for their targets. Syst. Synth. Biol. 2014, 8, 179-186. [CrossRef]

60. Howe, K.; FitzHarris, G. Recent insights into spindle function in mammalian oocytes and early embryos. Biol. Reprod. 2013, 3, 71-89.

61. Gorbsky, G.J.; Simerly, C.; Schatten, G.; Borisy, G.G. Microtubules in the metaphase-arrested mouse oocyte turn over rapidly. Proc. Natl. Acad. Sci. USA 1990, 87, 6049-6053. [CrossRef]

62. Hayden, J.H.; Bowser, S.S.; Rieder, C.L. Kinetochores capture astral microtubules during chromosome attachment to the mitotic spindle: Direct visualization in live newt lung cells. J. Cell Biol. 1990, 111, 1039-1045. [CrossRef]

63. Portran, D.; Schaedel, L.; Xu, Z.; Théry, M.; Nachury, M.V. Tubulin acetylation protects long-lived microtubules against mechanical ageing. Nat. Cell Biol. 2017, 19, 391-398. [CrossRef] [PubMed]

64. Zhang, M.; Dai, X.; Sun, Y.; Lu, Y.; Zhou, C.; Miao, Y.; Wang, Y.; Xiong, B. Stag3 regulates microtubule stability to maintain euploidy during mouse oocyte meiotic maturation. Oncotarget 2017, 8, 1593-1602. [CrossRef]

65. Mitchison, T.; Kirschner, M. Dynamic instability of microtubule growth. Nature 1984, 312, 237-242. [CrossRef]

66. Molle, G.; Decandia, M.; Ligios, S.; Fois, N.; Treacher, T.T.; Sitzia, M. Grazing management and stocking rate with particular reference to the Mediterranean environment. In Dairy Sheep Nutrition; CABI Publishing: Wallingford, UK, 2009 ; pp. $191-211$.

67. Ramirez, R.G.; Haenlein, G.F.W.; Núñez-González, M.A. Seasonal variation of macro and trace mineral contents in 14 browse species that grow in northeastern Mexico. Small Rumin. Res. 2001, 39, 153-159. [CrossRef]

68. Cabiddu, A.; Decandia, M.; Addis, M.; Piredda, G.; Pirisi, A.; Molle, G. Managing Mediterranean pastures in order to enhance the level of beneficial fatty acids in sheep milk. Small Rumin. Res. 2005, 59, 169-180. [CrossRef]

69. Requena, R.; Molina, P.; Fernandez, N.; Rodriguez, M.; Peris, C.; Torres, A. Changes in Milk and Cheese Composition Throughout Lactation in Manchega Sheep. In Proceedings of the 6th International Symposium on the Milking of Small Rumunants, Athens, Greece, 26 September-1 October 1990; EAAP Publ. No. 95; Wageningen Pers: Wageningen, The Netherlands, 1990.

70. Barron, L.J.R.; Fernández de Labastida, E.; Perea, S.; Chávarri, F.; Vega, C.D.; Soledad, V.M.; Isabel, T.M.; Isabel, N.A.; Virto, M.; Santisteban, A.; et al. De Seasonal changes in the composition of bulk raw ewe's milk used for Idiazabal cheese manufacture. Int. Dairy J. 2001, 11, 771-778. [CrossRef]

71. Nudda, A.; McGuire, M.A.; Battacone, G.; Pulina, G. Seasonal variation in conjugated linoleic acid and vaccenic acid in milk fat of sheep and its transfer to cheese and ricotta. J. Dairy Sci. 2005, 88, 1311-1319. [CrossRef]

72. Pulina, G.; Nudda, A.; Battacone, G.; Cannas, A. Effects of nutrition on the contents of fat, protein, somatic cells, aromatic compounds, and undesirable substances in sheep milk. Anim. Feed Sci. Technol. 2006, 131, 255-291. [CrossRef]

73. Mazzone, G.; Giammarco, M.; Vignola, G.; Sardi, L.; Lambertini, L. Effects of the rearing season on carcass and meat quality of suckling Apennine light lambs. Meat Sci. 2010, 86, 474-478. [CrossRef] 